\title{
Comparative Analysis of Aerial Photography with Instrumental Survey
}

\author{
Evgeniy Kuznetsov ${ }^{1}$, Galina Koretskaia ${ }^{2}$, and Asmelash Abay ${ }^{3}$ \\ ${ }^{1}$ T.F. Gorbachev Kuzbass State Technical University, Mezhdurechensk Branch, 652881, pr. \\ Stroiteley, 36, Mezhdurechensk, Russia \\ ${ }^{2}$ T.F. Gorbachev Kuzbass State Technical University, 28, Vesennyaya st., Kemerovo, 650000, \\ Russian Federaition \\ ${ }^{3}$ Department of Earth Science, College of Natural and Computational Sciences, Mekelle University, \\ Mekelle, Ethiopia
}

\begin{abstract}
At present, in Kuzbass, various methods of automation of plane surveys in open mining are used. In most cases, the choice of method depends on the material base of the enterprise and the professionalism of the performers. Typically, the work on the surveying automation consists in using electronic tachometers, which reduce time and simplify field and office work. However, the use of electronic tachometers remains the human factor and does not allow solving the problem of displaying the situation throughout the open pit at one physical moment of time. Aerial photography (AP) significantly increases the performance of plane surveys and makes it possible to most fully and reliably display the information about the surface and ensure the safety of fieldwork. The article presents a comparative analysis of the accuracy of constructing a digital terrain model obtained during aerial photography by $\mathrm{AN}-2$ aircraft and instrumental survey performed with electronic tachometer Leica TS 06 plus, by example of surveying a trench of section № 1 at Olzherassky open pit in the Kemerovo region. The advantages and disadvantages of AP from an airplane and prospects of using AP from an unmanned aerial vehicle (UAV) are given.
\end{abstract}

\section{Introduction}

Surveying is a crucial task on which a huge range of mining enterprise goals depends: from operating a separate technical unit to the issue of global subsoil safety.

At present, in Kuzbass, various methods of automation of plane surveys in open mining operations are used to improve the quality of field measurements and the reliability of reporting materials (plans, profiles, acts, justifications and other documents). In most cases, the choice of method depends on the material base of enterprise and the professionalism of the performers. Typically, the work on the surveying automation consists in using electronic tachometers, which reduce time and simplify field and office work. However, the use of electronic tachometers remains the human factor and does not allow solving the problem of displaying the situation throughout the open pit at one physical moment of time. Aerial photography (AP) significantly increases the performance of plane surveys and 
makes it possible to most fully and reliably display the information about the surface and ensure the safety of fieldwork.

Aerial photography is a set of works for obtaining topographic plans and digital terrain models (DTM) using materials photographing the terrain from an aircraft or from space [1].

For a long time, AP using airplanes has been the most common way to get air photos. The first successful experiments were made at the turn of the XIX-XX centuries. The most widely used aerial photography was then in the field of cartography - aerial photography survey. Photographing from aircraft is of great importance until nowadays, but its role is becoming less significant. Now, the relevance of aerial photography from aircraft remains in those areas where it is necessary to obtain coverage of a large area in the shortest time $[2]$.

The advantages of AP are:

- remote site research (non-contact method), which ensures the safety of fieldwork;

- high performance, ensuring the efficiency of solving surveying and technological problems;

- simultaneous registration of the state of the entire object or its individual part when dynamic processes occur;

- ensuring high accuracy in determining the geometric characteristics of examined object;

- completeness, objectivity and reliability of the results, because the photo image of the object is examined;

- maintaining the situation for a long time [3].

With the use of aerial surveying, a new source of information appears - an aerial photograph. Photo planes and photographs made from aerial photographs have metric properties, reflect in detail the status of work in a coal mine on a specific date and therefore can be effectively used for operational planning and management of mining operations. It is possible to solve various mining problems with the help of pictures. They include determining the slope angles of ledges, identifying places of water accumulation, determining the width of safety berms, monitoring the erosion of cut sides and dumps, controlling the layout of mining transportation equipment, the state of communications, drilling and blasting operations, etc. [4].

The aerial photography from an airplane involves the following operations: preparatory, field, photo laboratory, office.

In the preparatory period, the collection of available topographic information and aerial survey materials of past years is carried out. On their basis the variation strip of competitive route options are justified and a project for the production of aerial survey, field and office aerial surveying are drawn up.

In the field period, the ground-based geodetic work to create a planning-high-altitude substantiation of the AP; fixing and marking points of the reference network; various types of aerial surveys, the binding and decoding of aerial photographs are carried out.

Photo laboratory work includes deciphering of pictures - identification (detection and recognition) and disclosure of the content (cognition) of various objects and terrain elements by their images in the pictures, their qualitative and quantitative characteristics, peculiar properties and features.

In the office period, complete processing of the results of geodetic measurements, photogrammetric thickening of the geodetic survey justification using analytical phototriangulation methods, stereo photogrammetric work to obtain information about the terrain and the production of topographic plans and DTMs in a single coordinate system are performed [5].

Modern aerial photography is carried out using special survey and navigation equipment installed on an aircraft (airplane, helicopter) (Fig. 1). 
GPS / INS is used to determine the position of an image in space at any given time. The on-board computer and software allow integrating the processing of GPS receiver data and INS - inertial system data and combine the transformed pictures into full images. The laserlocation system is used to determine the flight altitude at the time of photographing. When processing aerial photographs (AP), the height is taken into account when calculating the coordinates of terrain points and determining the scale of the AP.

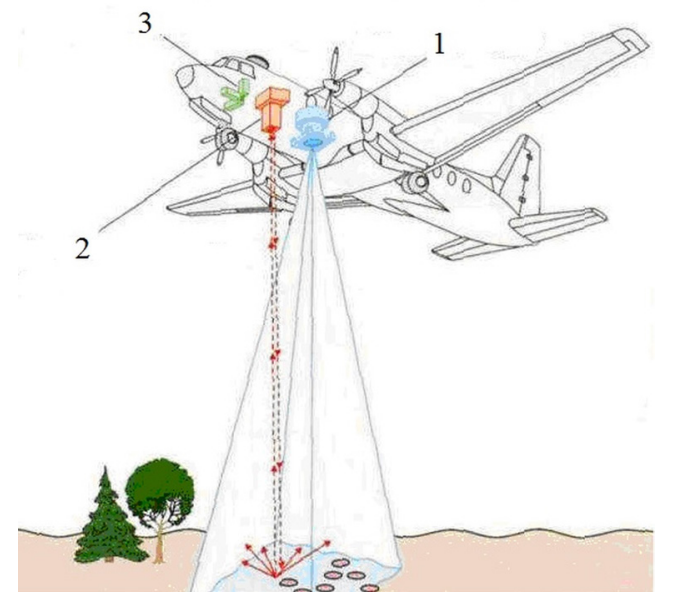

Fig. 1. Modern aerospace complex: 1) Global Positioning System and Inertial System (GPS / INS), 2) aerial camera, 3) laser location system.

In Kuzbass, the specialized units of the topographic-geodetic or land management service carry out the aerial photography work on specially equipped flying vehicles.

\section{Materials and Methods}

The article presents a comparative analysis of the accuracy of constructing a digital terrain model obtained during an aerial photography on AN-2 aircraft with instrumental surveys performed by electronic tachometer Leica TS 06 plus by the example of a trench survey of section № 1 at Olzherassky open pit in the Kemerovo Region.

Electronic tachometer Leica TS 06 plus is shown in Fig. 2, and the main technical characteristics are presented in Table 1.

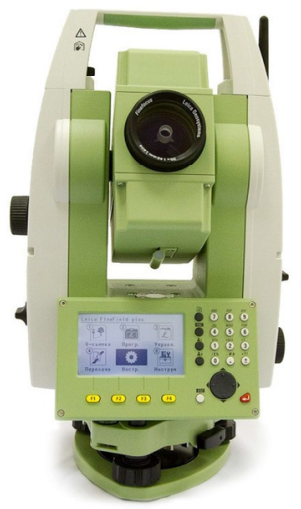

Fig. 2. Electronic tacheometer Leica TS 06 plus. 
Table 1. Technical characteristics of electronic tacheometer Leica TS 06 plus.

\begin{tabular}{|l|l|}
\hline Indicator & Value \\
\hline Angular Accuracy & $1 ", 2 ", 3 ", 5 "$ \\
\hline Range of measurement on one prism & $1.3-3500 \mathrm{~m}$ \\
\hline Accuracy of linear measurements on one prism & $\pm 1.5 \mathrm{~mm}+2 \mathrm{~mm} / \mathrm{km}$ \\
\hline Reflective Film Measurement Range & $1.3-400 \mathrm{~m}$ \\
\hline $\begin{array}{l}\text { Accuracy of linear measurements on reflective } \\
\text { film }\end{array}$ & $\pm 1.5 \mathrm{~mm}+2 \mathrm{~mm} / \mathrm{km}$ \\
\hline Range without reflector, R500 & $0.3-500 \mathrm{~m} ;$ \\
\hline Linear accuracy without reflector & $\pm 2 \mathrm{~mm}+2 \mathrm{~mm} / \mathrm{km} ;$ \\
\hline Telescope enlargement & $30 x ;$ \\
\hline Inner memory & 100000 points; \\
\hline Working hours & up to 20 hours on one battery; \\
\hline Battery Charge Time & up to 4 hours; \\
\hline Instrument weight & $5.2 \mathrm{~kg}$. \\
\hline
\end{tabular}

Electronic tacheometer Leica TS 06 plus has positive reviews in surveying practice. Its main advantage is high accuracy and reliability of angular and linear measurements. To store data obtained during the measurement, the electronic tacheometer has an internal hardware memory. It allows recording 100,000 points. This is more than enough to record the information of one working day. For use in non-standard situations, in conditions where it is not possible to download data periodically from the device, we can use external storage devices. The card reader installed in the device is adapted to work with ordinary flash cards through a USB connector, the maximum size of which does not exceed $180 \mathrm{~Gb}$. Also, for the convenience of the user, there is an additional serial port RS-232, optionally we can install the Bluetooth wireless module. The instrument is adapted for use at low temperatures and has an extended operating temperature range from $-30^{\circ} \mathrm{C}$ to $+50^{\circ} \mathrm{C}$.

To assess the accuracy of instrumental survey with an electronic tacheometer, aerial photography of the trench from the AN-2 aircraft was carried out. The average flight altitude was $1,500 \mathrm{~m}$.

For survey, we used a WILDRC-30 camera with interchangeable lenses, with a focal length of 150 and $90 \mathrm{~mm}$ with compensation for linear image shift, which allows getting high-quality pictures of $18 \times 18 \mathrm{~cm}$ format.

The camera also includes cartridges that hold $60 \mathrm{~m}$ of aerial film for 300 shots, the command device KPT-3, which provides automatic control of the aerial camera operating cycle at specified intervals between adjacent AP exposures from 1 to 100 seconds.

To transform the images, bringing them to a strictly horizontal position and a single predetermined scale, analytical photogrammetric devices SD-2000 and SD-3000 were used.

To decode the images and the resulting photographic plan, PhotoMod software was used in combination with stereo glasses and the WinMod surveying software [6].

The digital model was updated in PhotoMod software [6]. On this model, within the stereo-pair being processed, there are areas of work that are determined by paper plans on which their borders are plotted, and visually by the stereo model. After the place of work was determined, an exact identification of the boundary of the changes was performed. For each point of the stereo model, the corresponding points of the digital model were found.

Figure 3 shows a screenshot of the trench from the WinMod model at a scale of 1:2000, which includes the top and bottom boundaries from aerial photography and from an electronic tacheometer. 


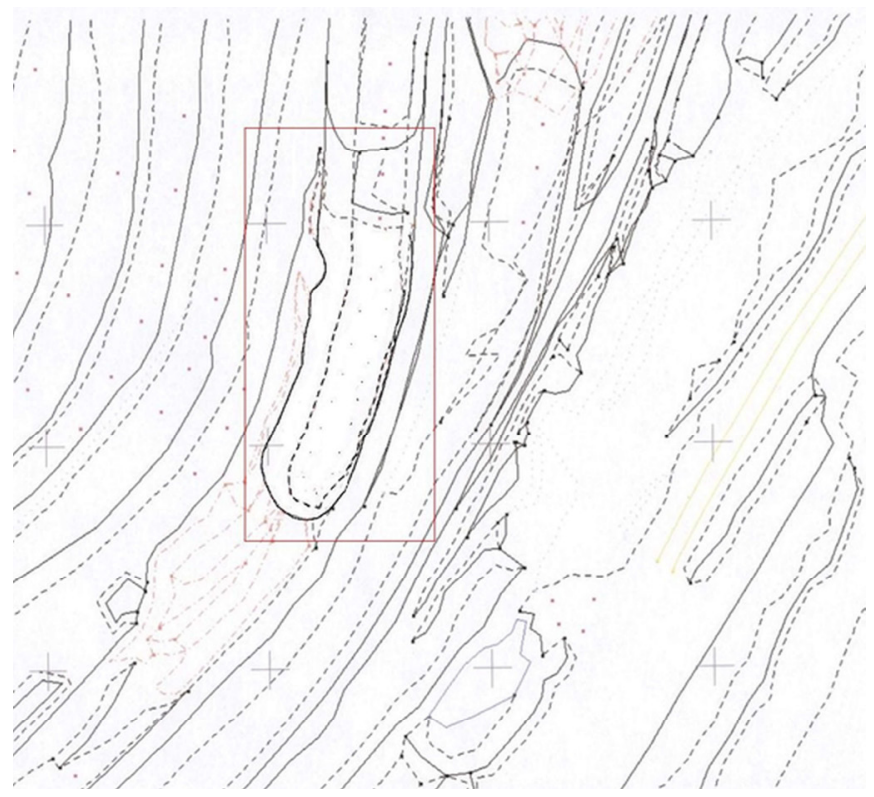

Fig. 3. Updated digital model WinMod.

The analysis of the results shows that the difference in the coordinates of the control points is so minimal that it is very difficult to determine visually the discrepancy of the lines, since the lines of the surfaces practically coincide.

During the instrumental survey, measurements were made at 48 control points on the contour and surface of the trench. Then, in PhotoMod software package, in stereo mode, the corresponding coordinates of the points on the topographic surveying plan of the aerial survey were found. While checking the processed data of the surveys in the planned and high-altitude positions, both surveys were in the same planes.

Table 2 shows a fragment of data for the first 12 points of a digital terrain model made using aerial photography and using Leica TS 06 plus tacheometer. The coordinate values presented in table 2 are conditional.

Table 2. Data fragment of a digital terrain model.

\begin{tabular}{|c|c|c|c|c|c|c|c|c|}
\hline \multicolumn{6}{|c|}{ Point coordinate values, $\mathbf{m}$} & \multirow{3}{*}{$\underset{\mathbf{m}}{\Delta \mathbf{X}}$} & \multirow{3}{*}{$\underset{\mathbf{m}}{\Delta \mathbf{Y}}$} & \multirow{3}{*}{$\underset{\mathbf{m}}{\Delta \mathbf{Z}}$} \\
\hline \multicolumn{3}{|c|}{ by aerial photography } & \multicolumn{3}{|c|}{$\begin{array}{c}\text { on instrumental } \\
\text { photography }\end{array}$} & & & \\
\hline $\mathbf{X}$ & Y & $\mathbf{Z}$ & $\mathbf{X}$ & Y & $\mathbf{Z}$ & & & \\
\hline 23.03 & 81.74 & 317.34 & 22.84 & 81.56 & 317.23 & 0.19 & 0.18 & 0.11 \\
\hline 49.61 & 25.63 & 317.54 & 49.47 & 25.44 & 317.68 & 0.14 & 0.19 & 0.14 \\
\hline 31.25 & 59.04 & 317.95 & 21.16 & 59.23 & 317.86 & 0.09 & 0.19 & 0.09 \\
\hline 25.31 & 88.10 & 317.63 & 25.46 & 87.94 & 317.78 & 0.15 & 0.16 & 0.15 \\
\hline 63.53 & 17.10 & 317.55 & 63.35 & 17.24 & 317.4 & 0.18 & 0.14 & 0.15 \\
\hline 35.53 & 44.59 & 317.95 & 35.34 & 44.42 & 317.82 & 0.19 & 0.17 & 0.13 \\
\hline 25.63 & 76.16 & 321.41 & 25.45 & 76.34 & 321.33 & 0.18 & 0.18 & 0.08 \\
\hline 27.77 & 70.40 & 321.86 & 27.89 & 70.27 & 321.98 & 0.12 & 0.13 & 0.12 \\
\hline 39.39 & 35.05 & 321.45 & 39.23 & 34.91 & 321.34 & 0.16 & 0.14 & 0.11 \\
\hline 38.06 & 39.73 & 321.88 & 37.91 & 39.91 & 321.73 & 0.15 & 0.18 & 0.15 \\
\hline 49.41 & 30.90 & 321.34 & 49.54 & 30.76 & 321.47 & 0.13 & 0.14 & 0.13 \\
\hline 49.81 & 25.63 & 321.56 & 49.62 & 25.08 & 321.67 & 0.19 & 0.17 & 0.11 \\
\hline
\end{tabular}




\section{Results and Discussion}

On Table 2 it is seen that the values of coordinates at the control points obtained by the method of aerial photography slightly differ from the data obtained using the Leica TS 06 plus tacheometer.

Thus, the digital model of the trench surface, constructed using the results of the AP, diverges from the mine plan, built on the basis of instrumental surveys with Leica TS 06 plus tacheometer, with a maximum deviation of $0.19 \mathrm{~m}$ in plan and $0.15 \mathrm{~m}$ in height. According to the requirements of the mine surveying production instructions [7], the error should not exceed $0.4 \mathrm{~mm}$ on the plan in the accepted survey scale and $0.2 \mathrm{~m}$ in height, that is, have a difference of not more than $0.2 \mathrm{~m}$ in the plan at a scale of $1: 2000$ and $0.2 \mathrm{~m}$ in height. Therefore, the deviations obtained are within acceptable values.

The experience gained in the field of AP using from an aircraft shows its exceptional effectiveness compared to traditional methods of collecting information both in terms of significant reduction in labor input and working time, and in terms of wide coverage of various types of information necessary for design.

Therefore, aerial photography can be used to control instrumental measurements performed by the surveying service in mining enterprises.

Nevertheless, aerial photography from an airplane has a number of significant drawbacks: it has low efficiency and requires high economic costs for maintenance and refueling, which leads to an increase in the final product cost. The cost of aerial photography is about 4 million rubles per year for a mining enterprise [6].

Currently, AP from an airplane is being replaced by new methods of survey and the creation of DTMs, such as laser scanning of terrain, and surveying from unmanned aerial vehicles (UAVs) [6].

Aerial photography using UAVs does not fundamentally differ from surveying using "large aircraft", but has certain features. UAV flight, as a rule, is performed at a cruising speed of $70-110 \mathrm{~km} / \mathrm{h}(20-30 \mathrm{~m} / \mathrm{s})$ in the altitude range $300-1500 \mathrm{~m}$. Non-metric household cameras with a matrix size of 10-20 megapixels are usually used for shooting. The focal length of the cameras is usually about $50 \mathrm{~mm}$ (in $35 \mathrm{~mm}$ equivalent), which corresponds to a local pixel size (GSD) of 7 to $35 \mathrm{~cm}$. Often, UAV images are processed using simple, non-strict methods (affine conversion of images to a plane). As a result, the user receives block layouts, which, in addition to low accuracy, may contain contour breaks at the joints of neighboring images $[7$.

In general, the use of UAVs for aerial photography and for obtaining cartographic accuracy materials shows economic efficiency and is more operational than AP from an airplane. For the widespread introduction of UAVs, it is necessary to create a regulatory framework and coordinate the efforts of both UAV manufacturers and their operating users, as well as developers of digital photogrammetric systems. One of the limiting factors for the introduction of UAVs for solving the above problems is the lack of practical experience in most organizations using them, as well as the lack of theoretically justified recommendations on the choice of surveying equipment for UAVs and the parameters of performed aerial photography using them [7].

\section{Conclusion}

1. Spatial-digital terrain models based on the results of instrumental surveying and aerial photography from an airplane have maximum differences of $0.19 \mathrm{~m}$ in plan and $0.15 \mathrm{~m}$ in height, which is within acceptable values. 
2. AP from an airplane provides the necessary accuracy of topographic surveys and the creation of digital telemetry thanks to modern navigation and location equipment, as well as reliable software for processing aerial photography data.

3. The advantages of AP include maintaining the situation for a long time, the absence of dead zones, high productivity. The main disadvantages are the high cost of equipment and auxiliary equipment, the dependence on weather conditions.

4. The UAV method is actively promoted in the media and scientific literature and is under development. The advantages of UAVs are high portability, flights at low altitudes (up to $300 \mathrm{~m}$ ), maintainability, automatic digitization of the photo-plan to a 3D model, low cost. The disadvantages of UAVs include:

- flight time limitation (no more than four hours) due to low battery charge and flight range $(50-70 \mathrm{~km})$ relative to the starting point;

- meteorological dependence (impact of wind, snow cover);

- less accuracy associated with unprofessional camera and the difficulty of fixing a large number of reference points;

- the need for triple overlapping of images along the longitudinal axis of $80 \%$, in the transverse direction of at least $40 \%$;

- lack of regulatory framework;

- difficulty in obtaining approval documents [8].

Nevertheless, the use of UAVs as an aerial survey platform has great prospects for solving surveying tasks when shooting short-range areal objects and linear objects, making it possible to obtain high-quality cartographic materials.

\section{References}

1. D. Szurgacz, J. Brodny, Sustainability, 11:9, 2570 (2019). DOI: doi.org/10.3390/su11092570

2. M. Tyulenev, O. Litvin, S. Zhironkin, M. Gasanov, Acta Montanistica Slovaca, 24:2, 88-97 (2019)

3. S. A. Syed, M. Z. Iqbal, M. M. Riaz, ISPRS Journal of Photogrammetry and Remote Sensing, 128, 326-337(2017)

4. D. Szurgacz, J. Brodny, Energies, 12:20, $3945 \quad$ (2019). DOI:doi.org/10.3390/en12203945

5. D. Szurgacz, J. Brodny, Energies, 13:2, 405 (2020). DOI:doi.org/10.3390/en13020405

6. J. J. Carrera-Hernández, G. Levresse, P. Lacan, J. J. Aranda-Gómez, Revista Mexicana de Ciencias Geologicas, 1:33, 122-133 (2016)

7. E. Dotsenko, N. Ezdina, S. Mudrova, E3S Web Conf., 41, 04050 (2018)

8. ASPRS, Photogrammetric Engineering \& Remote Sensing, 81:3, 1-26 (2015) 